\title{
The Application Discussion on Intelligent Technology in Electric Engineering Automation Control
}

\author{
Dai Rong \\ School of electrical engineering and automation, Anhui University,HeiFei,Anhui,230000 China \\ 119854632@qq.com
}

Keywords: Micro-class, Design standards, College teachers.

\begin{abstract}
Electric engineering automation control is kept in the important status of electric system. The construction of electric engineering automation control is directly related to stability of electric system operation. With the scientific development and improvement of automation level, the electrical engineering automation control gradually develops towards the intelligent direction. The intelligent application can effectively improve the overall level of electric automation control and promote overall development of electric engineering. Based on the theoretical foundation of intelligent technology, the author discusses the application of intelligent technology in electric engineering automation control.
\end{abstract}

\section{Introduction}

With the constant development of electric industry, the automation level is increasingly high. the intelligent technology is gradually presented in the electric engineering automation control. The intelligent technology can effectively overcome some difficulties in electric engineering automation and promote the rapid development of electric engineering. At present, intelligent technology has the great development potential in the electrical engineering field. The author will further analyze the application of intelligent technology in electric engineering automation control.

\section{Features of Intelligent Technology in Electric Automation Control}

The principle of applying intelligent technology in electric automation control application aims to realize control intelligence and humanization, reduce fault in control and save manpower and material resources. At present, the intelligent control has the following advantages in electric automation control by comparing with the traditional control:

A. Intelligent technology provides more convenience for electric system adjustment. The intelligent controller can use robustness and response time to realize the adjustment and control for the entire system, also effectively improve working efficiency, and enhance precision of automation control.

B. Intelligent technology enhances control precision. The traditional control mode can't accurately master dynamics of control objects for complexity of control objects, so as to take place unpredictable object factors in the control project. As a result, the model can't be well controlled for insufficient accuracy. The intelligent controller has no need to establish the object model, thus uncertain factors are reduced and precision of automation control can be enhanced.

C. The intelligent technology has the strong consistency. As dealing with different data issues, results by inputting different data are relatively ideal and meet automation control requirements. In addition, different control objects will result in diverse control effects. The controller doesn't have the control requirements for each control object, but the control effects are relatively ideal. At the same time, changes of some control objects will make control effects fail to reach the relevant requirements. As a result, in the automation control setting, it must begin with the actual situations. As evaluating the control, we can't blindly deny the automation control. It is necessary to find out specific causes for problems and solve it. 


\section{Specific Application of the Intelligent Technology in Electric Engineering Automation Control}

\section{A. Application of the Intelligent Controller}

Compared with the traditional controller, the application of the intelligent controller leaves out the modeling design process of the controlled objects, thus it can avoid from numerous uncontrolled factors in the initial stage, so as to improve the control precision of intelligent automation technology in electric engineering automation control. In addition, by virtue of constantly changeable robustness and controlling fall time and response time to automatically adjust control schedules of the system, the automation control of electric equipment can provide the favorable safeguard. Furthermore, the intelligent controller application is reflected in the adjustment control process of electric equipment. In terms of the intelligent controller, changes of relevant parameter data can realize self-adjustment, thus the field exploration of professionals has the lower requirements. According to the electric power principles, electric parameter voltage $\mathrm{U}$, current/power $\mathrm{P}$ and energy $\mathrm{W}$ can be directly calculated as follows:

$$
U=\sqrt{\frac{1}{T} \int u^{2}(t) d t} ; I=\sqrt{\frac{1}{T} \int i^{2}(t) d t} ; P=\frac{1}{T} \int u(t) ;(t) d t ; W(\tau)=\int u(t) \cdot(t) d t
$$

As detecting the current and voltage signal, electric quantity mutual inductor can't collect without time discontinuousness. Most of mutual inductors collect $\mathrm{N}$ voltage and current data in a fundamental wave period, thus the formula 1 can be converted into:

$$
U=\sqrt{\frac{1}{N} \sum_{k=1}^{N} u_{k}^{2}} ; U=\sqrt{\frac{1}{N} \sum_{k=1}^{N} i_{k}^{2}} ; P=\frac{1}{N} \sum_{k=1}^{N} u_{k} i_{k}
$$

The calculation of electric quantity applies the recursion formula in mathematics:

$\mathrm{W}_{\mathrm{j}}=\mathrm{W}_{\mathrm{j}-1}+\mathrm{u}_{\mathrm{j}} \mathrm{i}_{\mathrm{j}} \Delta \mathrm{t} \quad$ (Formula 3)

In the formula, $\mathrm{Wj}$ and $\mathrm{Wj}-1$ can calculate the energy accumulation from the beginning of energy counting to $\mathrm{j}^{\text {th }}$ and $\mathrm{j}-1^{\text {th }}$ of sampling. $\mathrm{uj}$ and $\mathrm{ij}$ are the instant voltage and current value of $\mathrm{j}^{\text {th }}$ sampling. $\Delta \mathrm{t}$ is the sampling interval. The calculation of power $\mathrm{S}$ and power factor $\cos \varphi$ is shown as follows:

$\mathrm{S}=\mathrm{UI} ; \cos \Phi=\mathrm{P} / \mathrm{S}$ (Formula 4 )

In terms of dealing with different data, the intelligent controller's control effects are different and this is determined by the controlled objects. In the actual operation process, when the controller controls some objects, it can be found that no action is taken, but the controlled objects still can reach the favorable control effects. However, it is worth noting that the controlled objects are still changed, which make control effects hard to reach the predicted target. As a result, in the process of designing the electric automation system, it must be based on the specific systematic design principles to comprehensively analyze different controlled objects. Rational selection or design intelligent controller can enhance control precision for all kinds of electric equipment.

\section{Design \\ B. Application of the Intelligent Technology in Fault Diagnosis and Electric Engineering}

By analyzing the electric engineering automation control system, it actually is a machine system, thus it inevitably will break down in operation process. The application of intelligent technology can timely diagnose and debug fault for automation control system, so as to minimize relevant loss. By taking the transformer fault as an example, when transformer in the electric system breaks down, the application of the intelligent automation control system can regard the leakage oil decomposition gas of the transformer as the media to powder the leakage oil and troubleshoot and confirm the fault position, so as to help workers to propose scientific overhauling scheme and maintain normal operation of relevant electric equipment.

The purpose of over voltage protection is to prevent too high busbar voltage from damaging the capacitor bank. As disconnecting the capacitor tank, reactive trend can't be changed at the same time, so as to reduce busbar voltage. 


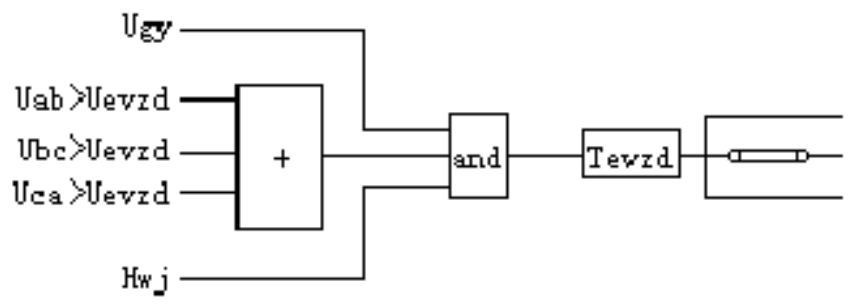

Fig.1 Schematic Diagram of Over Voltage Protection

The zero sequence voltage mainly judges the difference voltage of unbalanced voltage or open delta form. The schematic is shown in the figure:

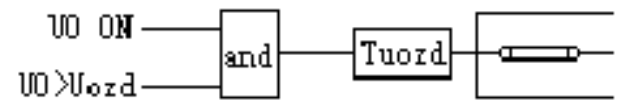

Fig.2 Schematic Diagram of Zero Sequence Voltage Protection

There is the internal fault protection in the capacitor tank, which is composed of multiple capacitors in series and parallel. When the insulation in the single capacitor breaks down, the respective configured fuse should be protected in a single one. The rated current of the fuse should 1.5-2 times of the single fuse's rated current.

The application of the intelligent technology in electric engineering automation control design mainly conducts the trial test for the main transformer, capacitor, mutual inductor and outlet line of their control, protection, status monitoring and system operation. The specific situation is shown as follows:

The main transformer, capacitor and mutual inductor relay protection are shown as follows:

Tab.1 Insulation Testing

\begin{tabular}{|l|l|l|l|l|l|l|l|l|}
\hline & $\begin{array}{l}\text { AC } \\
\text { voltage }\end{array}$ & $\begin{array}{l}\text { AC } \\
\text { current }\end{array}$ & $\begin{array}{l}\text { DC } \\
\text { power }\end{array}$ & $\begin{array}{l}\text { Tripping } \\
\text { and } \\
\text { closing }\end{array}$ & $\begin{array}{l}\text { On-off } \\
\text { input }\end{array}$ & $\begin{array}{l}\text { Signal } \\
\text { loop }\end{array}$ & $\begin{array}{l}\text { Automatic } \\
\text { dispatching } \\
\text { interface }\end{array}$ & $\begin{array}{l}\text { Over } \\
\text { the } \\
\text { ground }\end{array}$ \\
\hline $\begin{array}{l}\text { AC } \\
\text { voltage(Group } \\
\text { A) }\end{array}$ & - & $150 \mathrm{M} \Omega$ & $100 \mathrm{M} \Omega$ & $160 \mathrm{M} \Omega$ & $50 \mathrm{M} \Omega$ & $100 \mathrm{M} \Omega$ & $120 \mathrm{M} \Omega$ & $90 \mathrm{M} \Omega$ \\
\hline $\begin{array}{l}\mathrm{AC} \\
\text { current(Group } \\
\text { B) }\end{array}$ & - & - & $100 \mathrm{M} \Omega$ & $200 \mathrm{M} \Omega$ & $50 \mathrm{M} \Omega$ & $120 \mathrm{M} \Omega$ & $125 \mathrm{M} \Omega$ & $80 \mathrm{M} \Omega$ \\
\hline $\begin{array}{l}\text { DC } \\
\text { power(Group } \\
\text { C) }\end{array}$ & - & - & - & $200 \mathrm{M} \Omega$ & $50 \mathrm{M} \Omega$ & $120 \mathrm{M} \Omega$ & $130 \mathrm{M} \Omega$ & $70 \mathrm{M} \Omega$ \\
\hline $\begin{array}{l}\text { Tripping and } \\
\text { closing(Group } \\
\text { D) }\end{array}$ & $120 \mathrm{M} \Omega$ & $125 \mathrm{M} \Omega$ & - & $120 \mathrm{M} \Omega$ & $126 \mathrm{M} \Omega$ & $128 \mathrm{M} \Omega$ & $90 \mathrm{M} \Omega$ & $120 \mathrm{M} \Omega$ \\
\hline $\begin{array}{l}\text { On-off input } \\
\text { group D }\end{array}$ & $135 \mathrm{M} \Omega$ & $250 \mathrm{M} \Omega$ & $230 \mathrm{M} \Omega$ & $180 \mathrm{M} \Omega$ & - & $120 \mathrm{M} \Omega$ & $140 \mathrm{M} \Omega$ & $50 \mathrm{M} \Omega$ \\
\hline $\begin{array}{l}\text { Signal } \\
\text { loop(group E) }\end{array}$ & $200 \mathrm{M} \Omega$ & $270 \mathrm{M} \Omega$ & $255 \mathrm{M} \Omega$ & $200 \mathrm{M} \Omega$ & $125 \mathrm{M} \Omega$ & - & $150 \mathrm{M} \Omega$ & $60 \mathrm{M} \Omega$ \\
\hline $\begin{array}{l}\text { Automatic } \\
\text { dispatching } \\
\text { interface }\end{array}$ & $170 \mathrm{M} \Omega$ & $180 \mathrm{M} \Omega$ & $250 \mathrm{M} \Omega$ & $160 \mathrm{M} \Omega$ & $180 \mathrm{M} \Omega$ & $160 \mathrm{M} \Omega$ & - & $75 \mathrm{M} \Omega$ \\
\hline
\end{tabular}

On-off quantity input loop detection: 
Tab.2 Functional Pressing Plate Inspection

\begin{tabular}{|c|c|c|c|c|c|}
\hline No. & On-off quantity name & $\begin{array}{l}\text { Terminal } \\
\text { number }\end{array}$ & $\begin{array}{l}\text { Protection } \\
\text { plate status }\end{array}$ & $\begin{array}{l}\text { Management } \\
\text { plate status }\end{array}$ & Results \\
\hline 1 & $\begin{array}{l}\text { Differential protection } \\
\text { input }\end{array}$ & 2B29-2B7 & 1 & 1 & $\sqrt{ }$ \\
\hline 2 & $\begin{array}{lr}\text { Zero } & \text { sequence } \\
\text { differential } & \text { protection } \\
\text { input } & \\
\end{array}$ & 2B29-2B26 & 1 & 1 & $\sqrt{ }$ \\
\hline 3 & $\begin{array}{l}\text { I side alternating backup } \\
\text { protection input }\end{array}$ & 2B29-2B17 & 1 & 1 & $\sqrt{ }$ \\
\hline 4 & $\begin{array}{lr}\text { I side } & \text { ground zero } \\
\text { sequence } & \text { protection } \\
\text { input } & \end{array}$ & 2B29-2B22 & 1 & 1 & $\sqrt{ }$ \\
\hline 5 & $\begin{array}{l}\text { I side unground zero } \\
\text { sequence protection } \\
\text { input }\end{array}$ & 2B29-2B13 & 1 & 1 & $\sqrt{ }$ \\
\hline 6 & $\begin{array}{l}\text { II side alternating } \\
\text { backup protection input }\end{array}$ & 2B29-2B9 & 1 & 1 & $\sqrt{ }$ \\
\hline 7 & $\begin{array}{lr}\text { II side } & \text { ground zero } \\
\text { sequence } \\
\text { input }\end{array}$ & 2B29-2B10 & 1 & 1 & $\sqrt{ }$ \\
\hline 8 & $\begin{array}{l}\text { I side unground zero } \\
\text { sequence protection } \\
\text { input }\end{array}$ & 2B29-2B14 & 1 & 1 & $\sqrt{ }$ \\
\hline 9 & $\begin{array}{l}\text { III side backup } \\
\text { protection input }\end{array}$ & 2B29-2B8 & 1 & 1 & $\sqrt{ }$ \\
\hline 10 & $\begin{array}{l}\text { IV side } \\
\text { protection input }\end{array}$ & 2B29-2B12 & 1 & 1 & $\sqrt{ }$ \\
\hline 11 & $\begin{array}{l}\text { Public winding backup } \\
\text { protection input }\end{array}$ & 2B29-2B11 & 1 & 1 & $\sqrt{ }$ \\
\hline 12 & $\begin{array}{l}\text { Withdraw I side votlage } \\
\text { input }\end{array}$ & 2B29-2B16 & 1 & 1 & $\sqrt{ }$ \\
\hline 13 & $\begin{array}{l}\text { Withdraw II side votlage } \\
\text { input }\end{array}$ & 2B29-2B18 & 1 & 1 & $\sqrt{ }$ \\
\hline 14 & $\begin{array}{l}\text { Withdraw III side } \\
\text { votlage input }\end{array}$ & 2B29-2B19 & 1 & 1 & $\sqrt{ }$ \\
\hline 15 & $\begin{array}{l}\text { Withdraw IV side } \\
\text { votlage input }\end{array}$ & 2B29-2B15 & 1 & 1 & $\sqrt{ }$ \\
\hline
\end{tabular}

Tab.3 Output Connection Inspection of Tripping and Closing

\begin{tabular}{|l|l|c|c|c|}
\hline No. & $\begin{array}{l}\text { Tripping and closing } \\
\text { output name }\end{array}$ & Equipment terminal number & $\begin{array}{l}\text { Cabient terminal } \\
\text { number }\end{array}$ & Results \\
\hline 1 & Tripping I side switch & $\begin{array}{c}\text { 1A3-1A5, 1A7-1A9, 1A11-1A13, } \\
\text { 1A15-1A17 }\end{array}$ & 1CD1, 1CD23 & $\sqrt{ }$ \\
\hline 2 & Tripping II side switch & $\begin{array}{c}\text { 1A19-1A21, 1A23-1A25, } \\
\text { 1A27-1A29,1B1-1B3 }\end{array}$ & $1 \mathrm{CD} 3,1 \mathrm{CD} 25$ & $\sqrt{ }$ \\
\hline 3 & Tripping III side switch & $1 \mathrm{~B} 17-1 \mathrm{~B} 19$ & $1 \mathrm{CD} 17,1 \mathrm{CD} 39$ & $\sqrt{ }$ \\
\hline 4 & $\begin{array}{l}\text { Tripping I side } \\
\text { buscouple }\end{array}$ & $\begin{array}{l}\text { 1B5-1B7, 1B9-1B11,1B13-1B15 } \\
\text { Tripping III and IV side } \\
\text { section }\end{array}$ & $1 \mathrm{CD} 13,1 \mathrm{CD} 35$ & $\sqrt{ }$ \\
\hline 5 & $1 \mathrm{~B} 25-1 \mathrm{~B} 27$ & $1 \mathrm{CD} 21,1 \mathrm{CD} 43$ & $\sqrt{ }$ \\
\hline
\end{tabular}


The application of the intelligent technology in electric engineering design is mainly reflected in CAD technical development. To be specific, it is the application of genetic algorithm and expert system in electric product design. The genetic algorithm has the higher calculation precision, thus it is extensively applied in electric product design. It enhances product stability and also enhances product innovation degree. In expert system, the electric equipment fault has the significant non-linearity and uncertainty, but there is a close relation with various omens before breaking down. Expert system uses the artificial intelligent method and technology to troubleshoot the electric system fault by using the neural network and fuzzy logic. This effectively lengthens the lifetime of electric equipment and enhances production efficiency of equipment.

\section{Application of PLC}

PLC is the programming logic controller. The application in electric automation control is mainly reflected in electric system automation. In the thermal power plant, various technical processes of the auxiliary system give priority to switch control and sequent control. The constant improvement of productive index in electric industry enables relay in large-scale electric enterprise auxiliary system to be replaced by PLC. By virtue of PLC control system, it not only can realize the control for certain technical process, but also can coordinate the production work of the entire electric production department and enhance production efficiency. On the other hand, by analyzing cola handling system of the electric enterprises, it can be observed that in addition to auxiliary system, it also includes coal uploading, coal storage, coal downloading and coal matching system. The master station layer and remote IO station, as well as sensor on the spot are composed of the coal control system. The master station composed of PLC and man-machine system plays a crucial role on system control precision. The central control room gives priority to automatic control of PLC. Workers can realize the real-time monitoring for the system in line with the system display screen. In addition, after applying PLC, the object components in the power station control system are replaced by soft replay. This not only enhances system reliability, but also helps the power supply system to realize automatic switch and enhances precision for power supply system.

\section{Conclusions}

In the paper, the electric engineering automation control was used as the research background. The intelligent technology was considered as the research object. By simply analyzing the application of the intelligent technology in electric engineering automation control, the author conducted the systemic discussion and analysis for application of the intelligent technology in electric engineering automation control from intelligent controller, fault diagnosis, electric engineering design and programming logic controller. Research results indicate that the intelligent technology can effectively enhance working efficiency of different electric equipment, reduce fault occurrence, enhance fault maintenance efficiency, and finally promote sound and stable development of the electric engineering industry.

\section{References}

[1] Yu Chaosen, Application of the Intelligent Technology in the Electric Engineering Automation of the Power System[J], Electronic World, 2016, 19: 47+49.

[2] Wang Maoru, The Intelligent Technology Application Analysis Based on the Electric Engineering Automation[J], Electronic Production, 2016, 21:71-72

[3] Can Wenbin, Han Lijie and Xu Bin, Application of Intelligent Technology in Electric Engineering Automation Control[J], Inner Mongolia Science and Economy, 2015, 04: 69+ 72.

[4] Zhong Zhuojiang, Intelligent Technology Application Analysis of Electric Engineering Automation[J], Heilongjiang Science Information, 2017, 09:8.

[5] Chen TUo, Liu Hong and Hu Hui, Intelligent Technology Application Analysis Based on Electric Engineering Automation[J], Science Prospect, 2017, 06: 135.

[6] Zheng Zhimin, Application of Intelligent Technology in Electric Engineering Automation Control[J], Jiangxi Material, 2017, 08: 221-222. 